\title{
Allosteric Potentiator
}

National Cancer Institute

\section{Source}

National Cancer Institute. Allosteric Potentiator. NCI Thesaurus. Code C154903.

A class of substances that binds to a targ et allosterically and induces a conformational change in the target. This leads to an enhanced binding affinity of the target to its substrate, and thereby amplifies the effect of the substrate on that target. 